\title{
ORGANIZATIONAL INNOVATION AND COST REDUCTION ANALYSIS OF MANUFACTURING PROCESS - CASE STUDY
}

\author{
Senthil CHANDRAN \\ SACS MAVMM Engineering College \\ Robert POKLEMBA, Jakub SOPKO, LeOŠ ŠAFÁR \\ Technical University of Košice
}

\begin{abstract}
:
Innovation is the key to the growth of each business in a fast-changing world. Innovations affect financial activities because the successful innovation opens the new markets, gives the opportunity to reduce costs or introduce new products and services with a higher profit margin. Each organization, institution, enterprise or individual can be innovative. Innovations may not be implemented only in large enterprises, but also in medium or small. The aim of this paper is to innovate and optimize the polishing process in production plant with variant production. In this paper case study is used as research method which includes measurements and observation. The paper is focused on five variants of one product. We obtained the required data by measuring in a manufacturing plant in southern India in Madurai. At the end the results are summarized, and the optimization of the polishing process is proposed.
\end{abstract}

Key words: case study, innovation, small and medium enterprise (SME)

\section{INTRODUCTION}

In recent years, we face a high pressure on the modernization and digitalization in several areas of the economy worldwide. The modernization and digitalization were supported even more by implementation of the Industry 4.0 platform. For Small and Medium Enterprises (SMEs) this implementation requires a consistent sequence of introducing new innovations with an emphasis on monitoring costs of individual processes that are aimed to increase competitiveness. The main purpose of the innovation and digitalization is on the one hand to interconnect individual processes in the production and on the other hand the sustainability of the entire industry $[4,9]$. SMEs in developing countries must face the new requirements and fast modernization of production processes. During the last decade, India dragged attention thanks to high recorded GDP growth rate. According to World Bank [21] India will be the world's fastest growing economy in following years, hence we consider examining local SMEs beneficial. In this paper, we focus on a company operating in the steel industry in Madurai, Tamil Nadu, South India. Considering steel industry, India was the world's thirdlargest steel producer in 2017 and second largest in 2018 [17].

Various studies $[6,14,16]$ point to the importance of the SMEs in the centre of Indian economy, arguing that most of these enterprises are complementary to large trading companies, while lagging and less developed SMEs cause infrastructure problems that consequently lead to slowdown of the region development. Realizing necessity of innovations and limits bounded to SMEs' options, in this study we attempt to provide affordable and beneficial innovation solution in order to increase productivity of small-scaled local steel-fabricating producer using case study approach. Paper is therefore organized as follows: section 2 provides theoretical framework linked to case studies and productivity, while section 3 describes data collection and calculations. Consequently, in section 4 results and key findings are presented, section 5 concludes.

\section{THEORETICAL FRAMEWORK}

In this chapter we focus on methodological aspect of our study. Case study as a methodological approach and productivity as a measure of outputs' efficiency are described.

\section{Case study}

Case study, as a method widely used in empirical analyses, examines the current phenomenon in real situation in which multiple sources of information are used. The case study allows the researcher to examine the data in a specific context. As we present in Figure 1, in most cases, the case study is dealing with a particular area as a subject of investigation. Essentially, case study examines the current 
phenomenon of a real situation through the detailed contextual analysis with a limited number of events or processes, which represent the key input information. Observation methods have the potential to go beyond other methods that rely heavily or exclusively on their own research characteristics and procedures $[5,11]$.

Direct observation has been described as one of the most effective methods among the qualitative data collection techniques. Observing manufacturing processes avoids problems and simultaneously can also reveal shortcomings that are not accessible from other data collection methods, however, remain occasionally underestimated $[19,20]$.

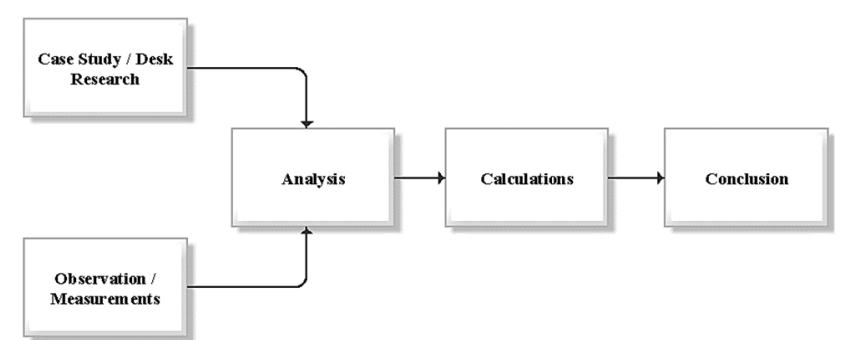

Fig. 1 Data collection methods and data analysis

Case studies are relatively flexible methods of scientific research. The Figure 2 shows the design of case study observational research, because the researcher himself is designing a research project, he provides the project with great freedom to discover and solve the problems he encounters during his research.

The case study enables the researcher to engage in more open and wider issues, and gradually narrow down and refine them according to the focus of the research [5]. In general, case study is important and useful method of collecting data, especially in cases of rare occurrences.

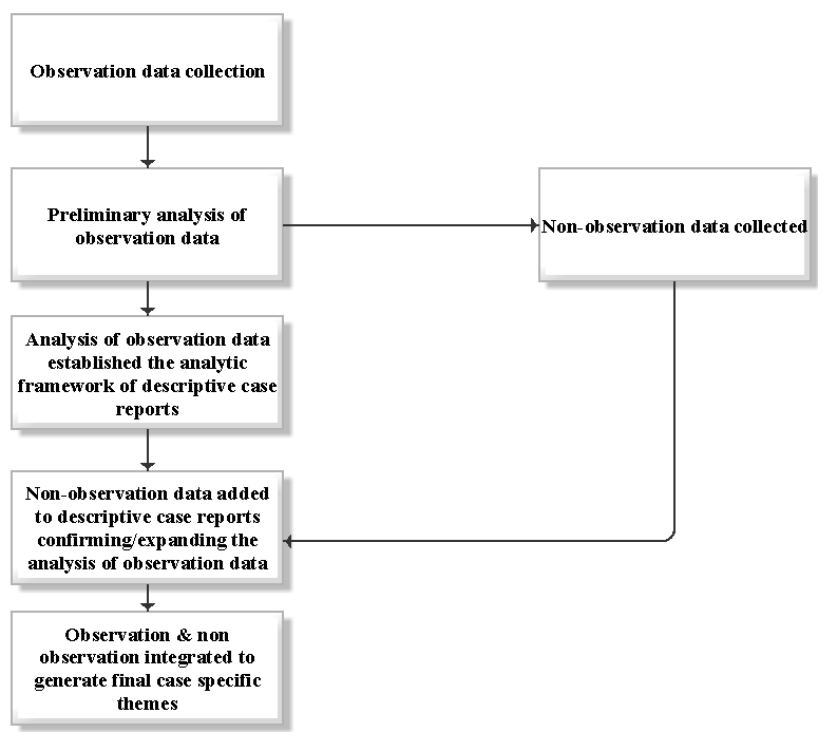

Fig. 2 Case study observational research/Single case Source: [12].

\section{Productivity}

The production process has been ongoing since the industrial revolution, for example in the area of logistics, information and innovation in machinery. Productivity is a long-term concept that includes a component of profitability, which is heavily influenced by the price paid for inputs and their transformation to outputs by the business entity. Productivity is a basic measure of the efficiency of the transformation process. As is shown in Figure 3 the productivity cycle consists of four main areas: measurement, evaluation, planning and improvement.

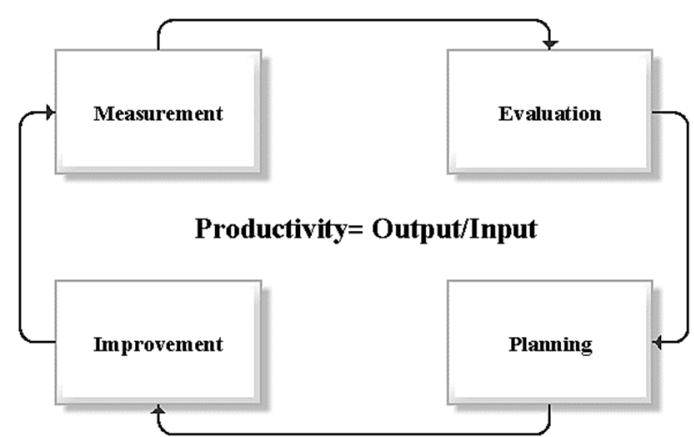

Fig. 3 Productivity

Source: [18].

Productivity measurement activity is crucial for an enterprise. Proper implementation and evaluation can lead towards reducing costs of production, storage or other work. Productivity of the company is being measured for several reasons such as monitoring the internal development of the enterprise, monitoring employees, monitoring the usage of material or outputs $[3,10]$.

The process of increasing labour productivity can be divided into several parts [18]:

- criteria selection - identifies measurable criteria on which productivity improvements will be assessed

- analysis of the current state

- draft concept of change - after analysing and defining the criteria, a proposal of methods and procedures will be developed to help increase productivity

- realization - designing and implementing changes

- evaluation and analysis.

\section{Application in local SME}

Even though case study is widely used, proper subject for effective and robust case study must be selected. We consider SMEs to be more appropriate for performing such case studies in contrast with large corporates, which often dispone with its own research resources. On the other hand, getting access to local SMEs with aim to collect data is often complicated. Background of this study is further explained in following paragraphs.

\section{Company examined}

Our empirical study has been performed based on observations and data collected from Pechiamman Stainless Steel, Ltd. $^{1}$ (referred as "PSS"). PSS is a small-scale ${ }^{2}$ indus-

\footnotetext{
${ }^{1}$ We would like to express our sincere gratitude to PSS representatives for providing an open minded and wide support and access, however, only limited information was permitted to be mentioned in our paper.

${ }^{2}$ At a time of data collection, number of employees was 19.
} 
try, operating in Madurai (Tamil Nadu, India), as a manufacturer of stainless-steel products. Its portfolio consists of (both final products and products intended for further adjustment) fabrication products such as vessels, chimneys, boilers, stoves, bakery stalls, tea machine stalls, sugarcane machine stalls, water heaters, staircase guides etc (see Table 1).

Table 1 Size of production

\begin{tabular}{|c|c|c|c|c|c|}
\hline $\begin{array}{l}\text { Name of the } \\
\text { Product }\end{array}$ & $\begin{array}{l}\text { of } \mathrm{Pr} \\
2018\end{array}$ & $\begin{array}{l}\text { Size } \\
\text { oduction } \\
\text { February } \\
2018\end{array}$ & $\begin{array}{l}\text { Actual Cost } \\
\text { (INR)*/kg }\end{array}$ & $\begin{array}{c}\text { Sales } \\
\text { Price } \\
\text { (INR)/kg }\end{array}$ & $\begin{array}{l}\text { Profit } \\
\text { (INR) }\end{array}$ \\
\hline Vessels & 180 & 15 & 360 & 440 & 80 \\
\hline Chimney & 24 & 2 & 340 & 440 & 100 \\
\hline Boilers & 600 & 48 & 380 & 450 & 70 \\
\hline Stove & 111 & 9 & 360 & 440 & 80 \\
\hline Bakery stall & 12 & 1 & 340 & 420 & 80 \\
\hline $\begin{array}{l}\text { Tea } \\
\text { machine stall }\end{array}$ & 12 & 1 & 360 & 440 & 80 \\
\hline $\begin{array}{l}\text { Sugarcane } \\
\text { machine stall }\end{array}$ & 120 & 10 & 360 & 440 & 80 \\
\hline $\begin{array}{l}\text { Water } \\
\text { heaters }\end{array}$ & 240 & 20 & 360 & 440 & 80 \\
\hline
\end{tabular}

*INR: Indian Rupee

Source: Own elaboration based on observations in PSS.

Considering productivity and effectiveness, after initial observations and discussions, we focused on fabrication of boilers considering budget and plant layout limitations based on discussions with PSS representatives. At the time of data collecting (for purposes of this study, we got permission from PSS only for one-month period - February 2018), producing boilers consumed almost half of production capacity PSS (based on observations shown in Table 1).

\section{Data collection and calculations}

Main separate inevitable operations of boiler fabrication are shown orderly in Table 2. These operations are same for various sizes of boilers (referred as "Products").

Table 2

Main operations

\begin{tabular}{|c|c|}
\hline \multicolumn{2}{|c|}{ Operations } \\
\hline Drawing & 01 \\
\hline Cutting & 02 \\
\hline Rounding & 03 \\
\hline Welding & 04 \\
\hline Malleting (Hammer) & 05 \\
\hline Tinkering & 06 \\
\hline Grinding & 07 \\
\hline Polishing & 08 \\
\hline Finishing & 09 \\
\hline
\end{tabular}

Source: Own elaboration based on observations in PSS in Feb. 2018.

Since 2018 PSS was producing five types of boilers with different parameters (volume in litres, weight in $\mathrm{kg}$ and size described by height and diameter in millimetres) as presented in Table 3 for products 1 (P1) to 5 (P5).
Table 3

Types of boilers produced in PSS in February 2018

\begin{tabular}{cccc}
\hline Products (Boilers) & $\begin{array}{c}\text { Volume } \\
\text { (Litres) }\end{array}$ & $\begin{array}{c}\text { Weight } \\
\text { (kg) }\end{array}$ & $\begin{array}{c}\text { Size } \\
\text { (height } \text { x diameter } \\
\text { in } \mathbf{~ m m} \text { ) }\end{array}$ \\
\hline P5 & 50 & 28 & $600 \times 450$ \\
P4 & 80 & 32 & $791 \times 483$ \\
P3 & 100 & 42 & $902 \times 524$ \\
P2 & 125 & 50 & $1067 \times 524$ \\
P1 & 150 & 60 & $1255 \times 524$ \\
\hline
\end{tabular}

Source: Own elaboration based on observations in PSS in Feb. 2018.

Consequently, median time was calculated separately for each product, based on 25 observations for each operation. For purposes of this paper, calculated median time will be considered as basic time [7]. Adding relaxation allowances (15\%) to basic time then should represent standard time - time needed for completing particular activity under standard circumstances [8]. Table 4 shows median observed time in minutes, which is described as basic time and median observed time in minutes included allowances (15\%), which points to standard time for each product and operations explained in Table 2. The time was measured by using stopwatch, while seconds were converted to cent minutes (for detailed discussion of using stopwatch methods in case studies see e.g. [2, 15]). Cost per kilograms was calculated based on data provided by PSS.

Table 4

Existing time of operations

\begin{tabular}{|c|c|c|c|c|c|c|c|c|c|c|c|}
\hline \multirow{2}{*}{$\begin{array}{l}\frac{n}{2} \\
\stackrel{0}{\pi} \\
\frac{0}{0} \\
\frac{0}{0}\end{array}$} & \multicolumn{5}{|c|}{$\begin{array}{l}\text { Median Observed Time in } \\
\text { Minutes (Basic Time) }\end{array}$} & \multicolumn{5}{|c|}{$\begin{array}{l}\text { Median Observed Time } \\
\text { in Minutes + Allowances } \\
\text { (15\%) (Standard Time) }\end{array}$} & \multirow[t]{2}{*}{ 苍 } \\
\hline & P1 & P2 & P3 & P4 & P5 & P1 & P2 & P3 & P4 & P5 & \\
\hline & 58.35 & 3.68 & 50.24 & 47.98 & 46.01 & 67.10 & 61.73 & 57.78 & 55.18 & 52.91 & 30 \\
\hline 2 & 49.50 & 45.54 & .26 & 40.71 & 39.08 & 56.93 & 52.37 & 49.75 & 4 & $4 k$ & \\
\hline 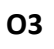 & 33.66 & .97 & 42 & 09 & 26.94 & 71 & ? & 33 & 3 & 3 & \\
\hline 4 & 61,19 & 56.30 & 53.65 & 50.46 & 48.39 & 70.37 & 64.75 & 61.70 & 58.0 & 55.65 & 1 \\
\hline 05 & 33.01 & 30.60 & 2 & 27.51 & 26.09 & 37.96 & 35.19 & 33.73 & 31.64 & 0 & 10 \\
\hline 6 & 61,19 & 56.47 & 52.78 & 49.88 & 47.60 & 70.37 & 64.94 & 60.70 & 5 & 5 & . \\
\hline D7 & 50.49 & 46.45 & 43.26 & 41.32 & 39.66 & 58.06 & 53.42 & 49.75 & 47.52 & 45. & 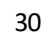 \\
\hline 08 & 59.40 & 54.65 & 51.92 & 49.58 & 47.60 & 68.31 & 62.85 & 59.71 & 57.02 & 54.74 & 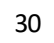 \\
\hline 09 & 32.67 & 30.60 & 28.55 & 27.09 & 26.00 & 37.57 & 35.19 & 32.83 & 31.15 & 29.90 & 10 \\
\hline $\begin{array}{l}\text { ग̃ } \\
\stackrel{0}{0}\end{array}$ & ఫ̊․ & 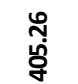 & 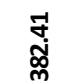 & ర్ర్ల & 商 & 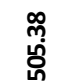 & 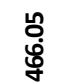 & $\begin{array}{l}\text { R. } \\
\text { gु }\end{array}$ & 家 & ণ্: & है \\
\hline
\end{tabular}

Source: Own elaboration based on observations in PSS in Feb. 2018.

Polishing is process for reducing, cleaning and shining defects on raw products. Firstly, we observed all the operations and measured the time they require. Next, we performed critical analysis $[1,13]$ in order to identify possible obstacles for processes of boiler manufacturing. Our critical analysis showed, that manipulation with raw products without proper machine, no proper fixation of product and size of polishing disc (during polishing process) are crucial for boiler manufacturing effectiveness. 
As Pischupen [13] suggests, performing critical analysis should lead to reducing time of operations or increasing efficiency of current operations, which can consequently reflect positively in reducing existing costs.

\section{Suggested implementation}

Firstly, we examined operations that require maximum time. From Figure 4 we see, that Operations 1, 4, 6 and 8 require high, similar portions of time. Additionally, considering 5 different product sizes, we can observe, that operations 1, 4, 6 and 8 tend to change more dynamically then other operations. Hence, we consider them more interesting with respect to possible time cutting.

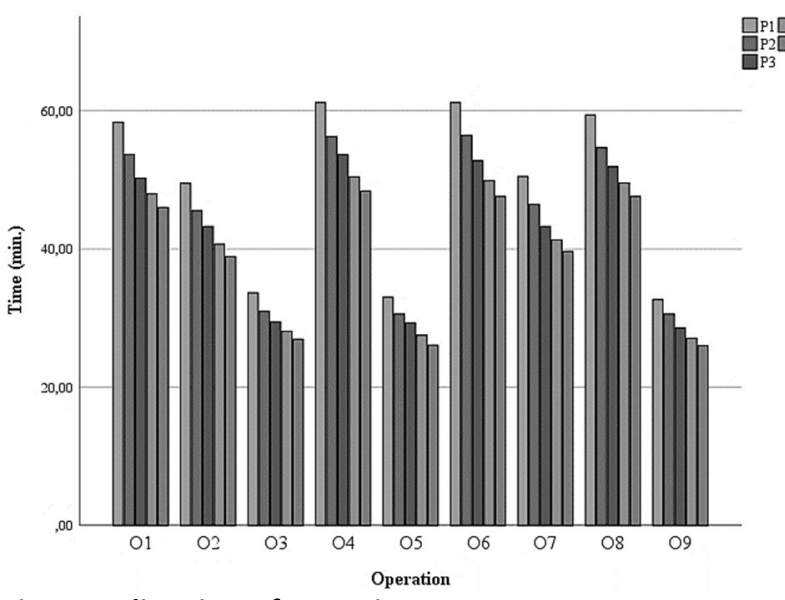

Fig. 4 Median time of operations

Source: Own elaboration based on observations in PSS in Feb. 2018.

Considering further plant layout, budget restraints given by PSS, and ability to implement innovative solutions in reasonable time frame, we focused further on operation 8 - polishing process, where implementing new machine (see Figure 5) was suggested. The Table 5 shows the specifications of the innovative component, which (based on our critical analysis) should reduce time needed for polishing process and consequently reduce costs of boilers production.

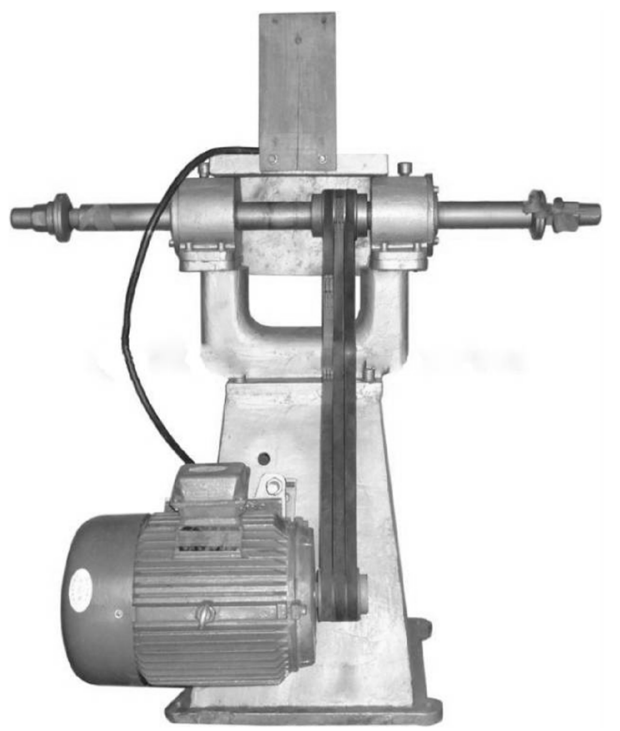

Fig. 5 Double head polishing machine

Source: Prem Brothers, Inc. (New Delhi, India).
Table 5

Polishing machine specification

\begin{tabular}{lc}
\hline Price & 800 US $\$$ \\
\hline Size & $1200 \mathrm{~mm} \times 1200 \mathrm{~mm} \times 600 \mathrm{~mm}$ \\
Motor power & $5.5 \mathrm{~kW}$ \\
Weight & $200 \mathrm{~kg}$ \\
\hline
\end{tabular}

Source: Prem Brothers, Inc. (New Delhi, India).

The Use:

- for polishing and grinding from different angle on different work pieces;

- two work stations allow 2 workers polishing or 2 polishing processes by 1 worker at a time;

- all casting parts ensure durable use;

- widespread use in process of polishing in different industries.

\section{Results and Discussion}

After implementing polishing machine, new time for polishing part of fabrication was set based on critical analysis of polishing process, respecting limitations of proposed machine, taking into account mainly size of surface of polishing disc, and less exhausting operational needs from workers' perspective. In general, we expect time needed for polishing via proposed way to be halved. After applying critical analysis, we provided the measurements with implemented polishing machine and we have obtained new data on the basis of which we expect costs of boilers production to decrease $40 \%$ [13].

\section{Estimations}

Actual cost is $380 \mathrm{INR} / \mathrm{kg}$, sale price equals to $450 \mathrm{INR} / \mathrm{kg}$, while actual time needed for polishing is stated in previous chapter. The Table 6 shows the measured times and cost of boilers production after proposed polishing machine implementation for each product:

Table 6

Measured time of operations after polishing machine implementation

\begin{tabular}{cccc}
\hline $\begin{array}{c}\text { Products/ } \\
\text { polishing } \\
\text { operation }\end{array}$ & $\begin{array}{c}\text { Measured } \\
\text { Basic Time } \\
\text { in Minutes }\end{array}$ & $\begin{array}{c}\text { Measured Basic Time } \\
\text { in Minutes } \\
\text { + Allowances (15\%) }\end{array}$ & $\begin{array}{c}\text { Cost } \\
\text { INR/kg }\end{array}$ \\
\hline P1 & 29.70 & 34.16 & \\
P2 & 27.33 & 31.42 & \\
P3 & 25.96 & 29.85 & $\mathbf{1 8}$ \\
P4 & 24.79 & 28.51 & \\
P5 & 23.80 & 27.37 & \\
\hline
\end{tabular}

Source: Own elaboration based on critical analysis of polishing process. Time presented in cent minutes.

\section{Cost/Benefit}

Based on time set by measurements and cost per kg in context with initial investment needed, we consequently present break-even point for this investment.

According to Table 7, proposed innovation would increase profit per kilogram from 70 rupees to 82 rupees, or 17.14\%. Considering initial investment 56800 INR (800 
$\mathrm{USD}^{3}$ ), we provide following calculations, suggesting kilograms or pieces of each product needed to be sold to return initial costs, also working days needed for reaching break-even point.

Table 7

Profit

\begin{tabular}{lcc}
\hline \multicolumn{1}{c}{ Conditions } & Actual Time & Measured Time \\
\hline Cost INR/kg & 380 & 368 \\
Sales Price INR/kg & 450 & 450 \\
Profit INR/kg & 70 & 82 \\
\hline
\end{tabular}

Source: Own elaboration based on observations in PSS in Feb. 2018.

From Table 8 we can conclude, that if we consider whole profit per kilogram as a repayment of initial investment, PSS will return those initial costs from 12 working days (or 12 pieces) considering $\mathrm{P} 1$, to 20 working days (or 25 pieces) considering P5. On the other hand, considering only excess return made of decreased time required for polishing, these results vary from 78 working days (considering P1) to 169 days (considering P5), respectively, to reach break-even point.

Table 8

Break-even point

\begin{tabular}{ccccc}
\hline $\begin{array}{c}\text { Pieces } \\
\text { needed } \\
\text { to break- } \\
\text { point }\end{array}$ & $\begin{array}{c}\text { Considering } \\
\text { excess profit } \\
\text { per kg (12 INR) }\end{array}$ & $\begin{array}{c}\text { Working } \\
\text { days } \\
\text { needed }\end{array}$ & $\begin{array}{c}\text { Considering } \\
\text { whole profit } \\
\text { per kg } \\
\text { (82 INR) }\end{array}$ & $\begin{array}{c}\text { Working } \\
\text { days } \\
\text { needed }\end{array}$ \\
\hline P1 & 79 & $\mathbf{7 8}$ & 12 & $\mathbf{1 2}$ \\
P2 & 95 & $\mathbf{8 6}$ & 14 & $\mathbf{1 3}$ \\
P3 & 113 & $\mathbf{9 7}$ & 17 & $\mathbf{1 5}$ \\
P4 & 148 & $\mathbf{1 2 0}$ & 22 & $\mathbf{1 8}$ \\
P5 & 169 & $\mathbf{1 3 1}$ & 25 & $\mathbf{2 0}$
\end{tabular}

\section{Kilograms}

needed

to break-

4733.3

692.7

point

Source: Own elaboration based on observations in PSS in Feb. 2018.

\section{CONCLUSION}

In this paper we focused on small-scaled company, Pechiamman Stainless Steel, Ltd., located in south India, Madurai, which operates in steel fabricating industry. Adopting case study approach, we firstly measured operations and processes within the company, secondly measured and observed data were analysed. Based on implemented critical analysis, we obtained new data and we are proposing innovation, which should reduce the polishing time by $40 \%$, and increase profit per kilogram sold by $17.14 \%$. We conclude, that proposed innovation of complex process is cost efficient. On the other hand, we faced layout and budget restraints, hence possibilities to provide more complex, innovative and effective solutions for examined enterprise were rather limited. To add on, we consider further case studies among similar industries and SMEs as crucial in order to support sustainability of region.

\section{ACKNOWLEDGEMENTS}

This paper is part of actual research activities in the project with acronym SME 4.0 and titled as "SME 4.0-Smart Manufacturing and Logistics for SMEs in an X-to-order and Mass Customization Environment" with funding received from the European Union's Horizon 2020 research and innovation program under the Marie Sklodowska-Curie grant agreement No 734713.

\section{REFERENCES}

[1] K. S. Al-Saleh. "Productivity improvement of a motor vehicle inspection station using motion and time study techniques." Journal of King Saud University-Engineering Sciences, vol. 23, no. 1, pp. 33-41, Jan. 2011.

[2] T. Brihaye, V. Bruyere and J. F. Raskin. "On model-checking timed automata with stopwatch observers." Information and Computation, vol. 204, no. 3, pp. 408-433, Mar. 2006.

[3] C. Duran, A. Cetindere, and Y.E. Aksu, "Productivity Improvement by Work and Time Study Technique for Earth Energy-glass Manufacturing Company," Procedia Economics and Finance, vol. 26, pp. 109-113, 2015.

[4] O. Ganschar, S. Gerlach, M. Hämmerle, T. Krause and S. Schlund. "Produktionsarbeit der Zukunft-Industrie 4.0," Ed. Dieter Spath, Stuttgart: Fraunhofer Verlag, 2013.

[5] T. Hollweck, "Robert K. Yin. (2014). Case Study Research Design and Methods ( $5^{\text {th }}$ ed.). Thousand Oaks, CA: Sage. 282 pages.," The Canadian Journal of Program Evaluation, Mar. 2016.

[6] B. Kalyani. "Problems faced by small scale entrepreneurs of the industrial estates of the Madurai region. "The ICFAI Journal of Management Research, vol. 7, no. 2, pp. 35-52, Jun. 2008.

[7] G. Kanawaty, Introduction to work study. Geneva, CH: International Labour Organization, 1992, pp. 524.

[8] M.M. Khatun. "Effect of time and motion study on productivity in garment sector." International Journal of Scientific \& Engineering Research, vol. 5, no. 5, pp. 825-833, May 2014.

[9] J. Konsek-Ciechońska, "Operational and Strategic Controlling Tools in Microenterprises - Case Study," Management Systems in Production Engineering, vol. 25, no. 4, pp. 278282, Dec. 2017.

[10] S. Lan, X. Wang and L. Ma, "Optimization of assembly line based on work study." Industrial Engineering and Engineering Management. IE\&EM '09. $16^{\text {th }}$ International Conference, vol. 4, pp. 813-816, Oct. 2009.

[11] M.J. Ligarski, "Methodology of Problem Analysis in the Quality Management System with the Use of Systems Approach." Management Systems in Production Engineering, vol. 26, no. 3, pp. 157-161, Oct. 2018.

[12] S.J. Morgan, S.R H. Pullon, L.M. Macdonald, E.M. McKinlay, and B.V. Gray, "Case Study Observational Research: A Framework for Conducting Case Study Research Where Observation Data Are the Focus," Qualitative Health Research, vol. 27, no. 7, pp. 1060-1068, May 2016.

[13] R. Pisuchpen, and W. Chansangar. "Modifying production line for productivity improvement: A case study of vision lens factory." Songklanakar in Journal of Science and Technology, vol. 36, pp. 345-357, 2014.

[14] P. Rao, S. Kumar and V. Madhavan. "A study on factors driving the capital structure decisions of small and medium enterprises (SMEs) in India." IIMB Management Review, vol. 31, no. 1, pp. 37-50, Mar. 2019.

\footnotetext{
${ }^{3}$ Average price, well within the limit of PSS (1000 USD).
} 
[15] R.S. Raut, and H.M. Deshmukh. "Productivity Improvement of a pre stress Concrete poleplant using Work study Technique." International Journal of Advanced Technology in Engineering and Science, vol. 2, no. 11, pp. 496-508, Nov. 2014.

[16] S. Sahoo and S. Yadav. "Total quality management in Indian manufacturing SMEs."Procedia Manufacturing, vol. 21, pp. 541-548, Mar. 2018.

[17] Trading Economics. "India Steel Production." Internet: https://tradingeconomics.com/india/steel-production, Dec. 28, 2018 [Jan. 22, 2019].

[18] M. Višnanský. "Increasing machine, line, human productivity." Internet: https://www.ipaczech.cz/cz/poradenstvi/ zvysovani-vykonnosti-procesu/zvysovani-produktivitystroje-linky-cloveka, Oct. 20, 2012 [Jan. 23, 2019].

\section{Chandran Senthil}

Department of Mechanical Engineering

SACS MAVMM Engineering College

Alagarkovil, Madurai 625301, Tamil Nadu, India

e-mail: senchandran@gmail.com

ORCID ID: 0000-0003-4524-4386

\section{Robert Poklemba}

Technical University of Kosice

Faculty of Manufacturing Technologies

Department of Industrial Engineering and Informatics

Bayerova 1, 08001 Presov, Slovak Republic

e-mail: robert.poklemba@tuke.sk

ORCID ID: 0000-0001-7269-6068

\section{Jakub Sopko}

Technical University of Kosice

Faculty of Economics, Department of Banking and Investment Němcovej 32, 04001 Kosice, Slovak Republic

e-mail: jakub.sopko@tuke.sk

ORCID ID: 0000-0002-7314-828X

\section{Leoš Šafár}

Technical University of Kosice

Faculty of Economics, Department of Finance

Němcovej 32, 04001 Kosice, Slovak Republic

e-mail: leos.safar@tuke.sk

ORCID ID: 0000-0001-8466-0644
[19] C. Walshe, G. Ewing, and J. Griffiths, "Using observation as a data collection method to help understand patient and professional roles and actions in palliative care settings," Palliative Medicine, vol. 26, no. 8, pp. 1048-1054, Dec. 2011.

[20] C. Walshe, C. Chew-Graham, C. Todd and A. Caress, "What influences referrals within community palliative care services? A qualitative case study." Social science \& medicine, vol. 67, no. 1, pp. 137-146, Jul. 2008.

[21] World Bank. "Global Economic Prospects, June 2018: The Turning of the Tide?," Global Economic Prospects, Jun. 2018. 